\title{
AC 2008-1848: GETTING STUDENTS ON THE RIGHT TRACK: A STUDY OF EXIT SURVEYS IN A FIRST YEAR ENGINEERING PROGRAM
}

\section{Jim Chamberlain, Clemson University}

Jim F. Chamberlain is a Ph.D. student at Clemson University in Environmental Engineering and Earth Sciences. He received his M.S. in Environmental Systems Engineering from Clemson in 1994 and has worked as an environmental consultant for 12 years. His research interests are in the environmental impacts of growing monocultural switchgrass as a biofuel. Jim is a registered

professional engineer and a member of the American Society for Engineering Education.

\section{Lisa Benson, Clemson University}

Lisa C. Benson is an Assistant Professor in the Department of Engineering and Science Education, with a joint appointment in the Department of Bioengineering, at Clemson University. Her research areas include engineering education and musculoskeletal biomechanics. Education research includes the use of active learning in undergraduate engineering courses, undergraduate research experiences, and service learning in engineering and science education. Her education includes a B.S. in Bioengineering from the University of Vermont, and M.S. and Ph.D.degrees in Bioengineering from Clemson University. 


\title{
Getting Students on the Right Track: Exit Surveys and Levels of Awareness in First Year Engineering Students
}

\begin{abstract}
The goals of a first year engineering program are to both provide students with a sound academic preparation for engineering study, and to allow them to explore various engineering disciplines. Through academic advising and career counseling, our program helps students discover the career path that is right for them. We find that about $30 \%$ of students choose to leave engineering by the end of their first year of study. These students voluntarily complete an Exit Survey, which includes questions on their level of certainty upon entering the program, people with whom the decision to leave was discussed, the primary motivating factors both to enter and to leave engineering, and what appeals to them about their new majors. We have analyzed over 400 of these Exit Surveys over a four-year period to examine correlations between gender, choice of new major, reasons for leaving, and the impact of different program resources. The study also demonstrates how the survey results can inform and enhance the different aspects of a first year engineering program.
\end{abstract}

Survey responses show that students vary in their levels of a) understanding the robustness and diversity of engineering as a profession, b) comprehending the need for the foundational concepts presented by math, physics and chemistry, and c) willingness to immerse one's self in a difficult course of study. A phenomenographic approach is being used to divide survey responses into categories, which can then be correlated to various survey parameters, such as gender, level of certainty upon entering the program, and reasons for leaving engineering.

\section{Introduction}

Engineers use the tools of physics, chemistry and mathematics to solve increasingly complex problems in today's world. The pool of qualified engineers in the United States has decreased by about $20 \%$ since 1985 , as indicated by the number of engineering bachelor's degrees earned by U.S. citizens and permanent residents ${ }^{1}$. Furthermore, fewer than half of those students who enter as engineering and science majors complete their degrees within five years.

First year engineering programs can perhaps do little to attract new students into their programs. In a generation that is highly media-saturated, engineering as a profession does not enjoy the exposure and dramatic excitement from film and television that are accorded other professions, such as medicine, law, and forensic analysis. Thus, when a student enters a four- to five-year engineering program, they can be expected not only to have questions about what an engineer is supposed to learn but also about what an engineer actually does upon graduation. Only as these become known to the student, can 
he or she then ask whether or not their own particular skills, interests and passions are a good fit for the arduous engineering journey. Some students will persist on the path chosen; others will leave at various stages in this road to discovery.

Quantitative survey tools have been useful in allowing researchers to catalog the differences between "non-switchers" (persisters) and "switchers" (non-persisters) ${ }^{2}$. Closed-form surveys can be efficient ways to objectively measure general attitudes and impressions of students about engineering over a large group and to give a sense of success / failure indicators.

Qualitative studies have sought to produce more holistic conclusions about the most important factors of a student's experience before, during and after (expectations) college so as to direct advising and administrative resources properly. Seymour and Hewitt's three-year study of STEM students identified reasons for switching away from STEM fields as related to classroom instruction, departmental culture (attitudes and practices of engineering faculty), and institutional structure (curriculum requirements, advising, counseling and tutoring services) ${ }^{3}$. Heavy curriculum demands in the number of required course hours forced a student to commit to an engineering discipline too early in their academic life, even before having had a chance to learn much about that particular discipline as a career ${ }^{4}$. If students wait to declare a major, they may fall behind in the curriculum schedule.

The purpose of this study is to present the results of an analysis of over 400 exit surveys, collected over a four-year period, in order to examine the impact of various factors, such as gender and initial level of certainty about being an engineer, on the number and types of students who leave engineering and the reasons why they leave. The study also looks at categories of decisions within which students make the decision to leave. Such an analysis has the potential to inform and enhance the effectiveness of advising, mentoring, curriculum, and other aspects of a first year engineering program.

\section{First Year Engineering Program at Clemson University}

The goals of the first year engineering program are both to provide students with a sound academic preparation for engineering study and to allow them to explore various engineering disciplines. Two sequential introductory engineering courses ( 5 credit hours), two calculus courses, and one course each in physics, chemistry and English comprise the "threshold curriculum" which first year engineering students must master before being admitted to a specific discipline. At Clemson University, the General Engineering curriculum was recently modified to include presentations given by each engineering discipline department on campus along with tours of the individual departments. Through academic advising and career counseling, the program helps students discover the career path that is right for them. 


\section{Exit Surveys}

For students who choose to move on to another major outside of engineering, exit surveys are one mechanism that is useful for tracking the reason(s) for "non-persistence". Students who decide to change their major out of engineering are asked to complete a survey that included both closed-ended questions (multiple-choice) and open-ended questions about their reasons for leaving and factors that helped them make that decision. The survey takes approximately 5 minutes to complete.

Close-ended questions included personal information such as gender and number of semesters in engineering, as well as the following questions.

- When you started in General Engineering, how certain were you that engineering was what you wanted to study? (Very certain, Not very certain, Felt I was expected to pursue engineering)

- What made you decide to leave engineering? (check all that apply):

○ To keep my scholarship.

- My GPR isn't high enough to declare an engineering major.

- The courses are too hard (list courses)

$\circ$ I really am more interested in another field.

- I'm ready to get a degree in something, and engineering will take too long.

- I took interest inventories that helped me see that I'll be happier in this new field.

- General Engineering class(es) helped me see that engineering isn't what I want to do (list courses)

"Interest inventories" refer to one of various assessment tools given to students over the course of this study to help them discern their personal strengths, talents and interests. These include the Self-Directed Search $\odot /$ Holland Index (Psychological Assessment Resources, Inc, www.self-directed-search.com), the Cognitive Profile Inventory by Lois Krause (Thompson Custom Publishing, Cinncinati, OH), a modified Myers-Briggs survey (Keirsey Temperament Sorter@, Prometheus Nemisis Book Company, San Mateo, CA, www.keirsey.com), and the TypeFocus ${ }^{\mathrm{TM}}$ Survey (TypeFocus Internet, Inc, www.typefocus.com). This information is used by academic advisors within the General Engineering program to help students make informed decisions about their education and career goals.

Two open-ended questions were also included:

- What appeals to you about your new major?, and

- Additional comments?

In approaching the exit surveys, we were especially interested in the hand-written comments that were made to these latter two questions. All students were asked to respond to the first question. Responses to the second question tended to be either further elaborations of the first question response or incidental comments, both positive and negative, about the General Engineering program or other engineering programs within 
the college. In both cases it can be assumed that students were not given, and did not take, much time to think through reasoned, reflective responses. Rather we assume that we are reading first-impression, instinctive reactions that trigger accurate responses, albeit unrefined and blunt at times. This perspective, we feel, makes the responses that much more illuminating.

\section{Methods}

This study analyzed over 400 of these exit surveys, collected over a four-year period (2002-2006), to examine correlations between gender, choice of new major, reasons for leaving, and the impact of different program resources. All exit survey responses were entered into a spreadsheet. All methods were approved by the Institutional Review Board; confidentiality of student identities and survey responses were maintained throughout the study.

\section{Statistical Analysis of Close-Ended Responses}

Differences in proportions of responses to the close-ended questions were determined using chi-square tests. Comparisons of proportions were made between responses by male and female students, and between responses by students with different levels of certainty upon entering the program (very certain, not very certain, or expected to pursue engineering). The null hypotheses for these analyses were that proportions of responses were equal among the groups being compared. If the null hypothesis was rejected (i.e., differences existed in the proportions among the groups), then pairwise comparisons among each of the groups were performed to determine the specific groups that had significantly higher or lower proportions of responses. All chi-square tests were performed with the Statistical Analysis System (SAS Version 9.1, Cary, NC) using an alpha level of 0.05 .

\section{Qualitative Analysis of Open-Ended Responses}

In order to qualitatively analyze the survey responses, we devised a system of category descriptions similar to those employed in phenomenography. The aim of phenomenography as a research methodology is to reveal the different and unique ways of experiencing a phenomenon, such as physical occurrences (velocity, torsion or price; Marton and Pong, 2005), or a concept, such as the idea of engineering as an educational or career goal. The assumption in such studies is that there are a limited number of qualitatively different ways in which a phenomenon, or focus topic, will be encountered. Upon appropriate levels of analysis, a researcher can make statements about the situation or topic or phenomenon as experienced by the subject or student. In this case the object of study is not the phenomenon per se, but the relationship between the subject and the phenomenon. Figure 1 shows how there are a number of different ways that students may think of themselves in engineering, using categories. 


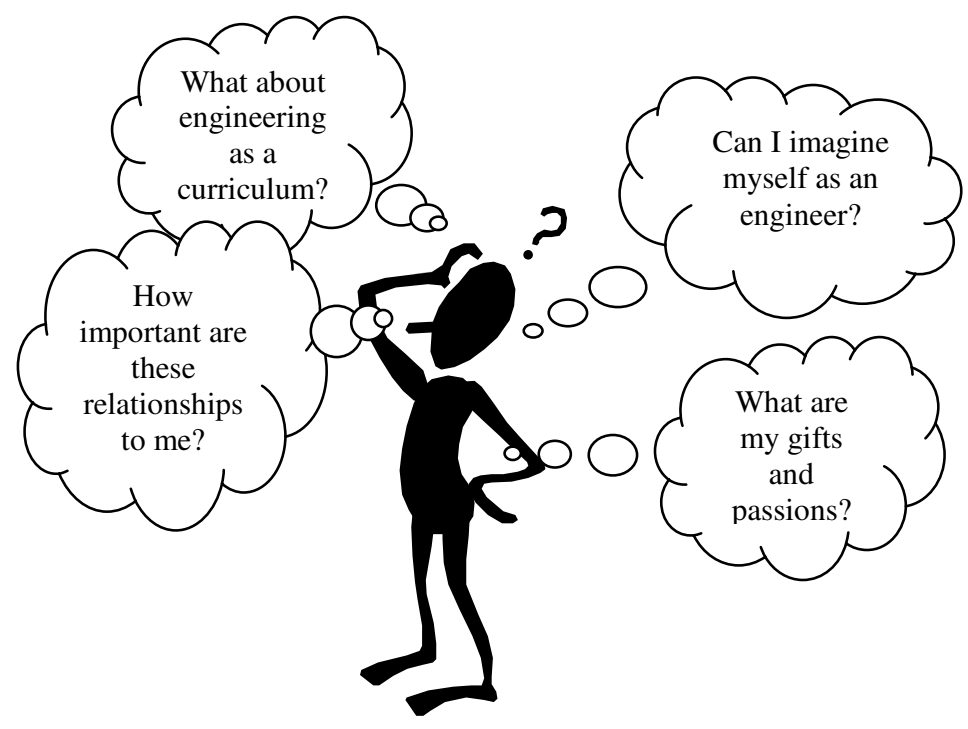

Figure 1. Questions that students may reflect on when thinking about engineering, categorized from a phenomenographic perspective.

Phenomenographic interviews are typically longer interviews with a series of questions that may change direction or focus as per the interviewer's discretion. The interview transcripts (often audio-recorded) then become the text of the analysis. A set of categories or meanings are deduced by the researcher based on the record of these transcripts. The categories are not pre-devised, but "emerge" from the data in an organic fashion 5 . These categories of description are further analyzed with regards to their similarities and differences, and, to the extent that they relate to one another logically, form a universe (or pool) of meaning ${ }^{6}$. There are no judgments made regarding the categories. The goal of the method is that every unique experience articulated by the individuals in the sample population is accounted for in some category.

Although we are not doing phenomenographic research, we are applying similar understandings in order to delineate the categories of responses that students give when asked to briefly reflect upon and describe their experience in engineering. These categories are not pre-determined, but arise from the responses themselves.

The open-ended survey responses were read in entirety by one member of the research team, who then constructed an initial set of categories in terms of referential and structural aspects (linguistic markers). A second read-through was necessary to produce this first draft of descriptions within those categories. The category descriptions emerged only as the data revealed them; there was no presupposed initial set. A second researcher reviewed the responses, categories and category descriptions, and offered refinements. Once these components were discussed and debated, a final consensus version of categories and descriptions was determined. Table 1 presents the findings of this consensus.

The following categories of description capture the responses of this sample of students:

1. Profession: the experience of engineering as a suitable and rewarding profession (or attraction to an alternate profession as suitable and rewarding) 
2. Curriculum: the experience of the threshold engineering curriculum (or attraction to an alternate curriculum)

3. Relational: the experience of the personal, relational aspect of an engineering field and/or curriculum, e.g., the personnel associated with the threshold engineering curriculum (or attraction to personnel associated with another curriculum)

4. Self-awareness: the experience of a self-awareness of one's personal strengths, motivations, and passions

5. Institutional: the experience within the General Engineering program or other engineering departments overshadows other aspects of the first year experience

Table 1. Categories of description with typical characteristic responses as linguistic markers for answers to the questions: What do I like about my new major? and

Additional Comments?

\begin{tabular}{|c|c|c|}
\hline $\begin{array}{l}\text { Categories of } \\
\text { Description }\end{array}$ & $\begin{array}{l}\text { Points of } \\
\text { Reference }\end{array}$ & $\begin{array}{l}\text { Linguistic Markers } \\
\text { (examples) }\end{array}$ \\
\hline \multirow{3}{*}{ Profession } & $\begin{array}{l}\text { Engineering not rewarding / appealing } \\
\text { ("pushed from") }\end{array}$ & $\begin{array}{c}\text { "do what I want to do instead of filling a mold" } \\
\text { "(new field) deals mainly with people rather than } \\
\text { with things" }\end{array}$ \\
\hline & $\begin{array}{l}\text { Other profession more appealing } \\
\text { ("pulled towards") }\end{array}$ & $\begin{array}{l}\text { "the number of options for a career (in new field)" } \\
\text { "more money to be made" }\end{array}$ \\
\hline & $\begin{array}{l}\text { Misunderstanding of engineering as a } \\
\text { profession }\end{array}$ & $\begin{array}{l}\text { "I can do project management (in new field)" } \\
\text { "actual practical knowledge (in new field)" }\end{array}$ \\
\hline \multirow{3}{*}{ Curriculum } & $\begin{array}{l}\text { Engineering courses too difficult / } \\
\text { curriculum too long }\end{array}$ & $\begin{array}{c}\text { "graduating on time (in new field)" } \\
\text { "the variety of classes I have the option to take(in } \\
\text { new field)" }\end{array}$ \\
\hline & Engineering courses unappealing & $\begin{array}{l}\text { "there are too many regulations on how one } \\
\text { completes assignments" }\end{array}$ \\
\hline & Other courses more appealing & $\begin{array}{c}\text { "working with circuits and electronics appeals to } \\
\text { me" } \\
\text { "interested in politics and world affairs" }\end{array}$ \\
\hline Relational & $\begin{array}{c}\text { Personnel / personalities appealing or } \\
\text { unappealing }\end{array}$ & $\begin{array}{l}\text { "my dad offered to have me take over his } \\
\text { accounting practice" } \\
\text { "the type of people I would be working with (new } \\
\text { field)" }\end{array}$ \\
\hline \multirow{3}{*}{ Self-Awareness } & $\begin{array}{l}\text { Original motivation was misguided or } \\
\text { in error }\end{array}$ & $\begin{array}{c}\text { "I was pushed into it" } \\
\text { "My dad wanted me to be an engineer because he } \\
\text { was" }\end{array}$ \\
\hline & Greater appreciation of core strengths & $\begin{array}{l}\text { "I am not a math-oriented person" } \\
\text { "My personal talents fit better in a business field" } \\
\text { "I have on-job experience (in new field)" }\end{array}$ \\
\hline & $\begin{array}{c}\text { Greater appreciation of core passions or } \\
\text { enjoyment }\end{array}$ & $\begin{array}{c}\text { "I love the whole 'sport' field and } \\
\text { it seems fun" } \\
\text { "more my personality" } \\
\text { "I enjoy the programming side of computers rather } \\
\text { than the hardware" } \\
\text { "math is something I enjoy and excel at" }\end{array}$ \\
\hline Institutional & $\begin{array}{l}\text { Disappointment with the General } \\
\text { Engineering department }\end{array}$ & $\begin{array}{l}\text { "when class test averages are } 40 \% \text {, there is } \\
\text { definitely something wrong" } \\
\text { "I did not receive work back in a timely manner } \\
\text { which turned out to hurt me on a test" } \\
\text { "despite some of the best efforts, I still felt like just } \\
\text { another number" }\end{array}$ \\
\hline
\end{tabular}


Each of the categories is discussed below.

Engineering as a profession. Responses within this category fell into two groups, or descriptions. One group of students made the decision to leave because of their experience of engineering as a career that is unsuitable or unattractive to them. The second group found an alternative career as more suitable or attractive. Those of the first type may be considered to have been "pushed" out of consideration of engineering as a profession. Responses typical of such a group are those students who felt that engineering was not "creative" enough or did not call upon their "artistic" abilities. The responses often reflected the student's experience of engineering to this point - e.g., my new career will be "less group-based" or "deals mainly with people rather than with things". The second group, which comprised a large number of respondents than the first, felt "pulled" more towards a different profession. Typical responses were: "I love the field", "I like to deal with people and products in the consumer market", "I am able to deal with children" and, of course, "money". Some responses showed, usually indirectly, that the student was not aware of the breadth and diversity of engineering careers, including careers in which engineering knowledge was essential to obtaining management positions. Some students did not realize that engineers could "work outdoors", use "actual practical knowledge", or "have applications", or could be engineers without "filling a mold". Such responses reflect an incomplete first look at the occupation of engineering, one that could perhaps be remedied by additional enhancement in the threshold classes.

Engineering as a curriculum. The engineering curriculum is intense and robust, and not easy to complete in a typical four-year, eight-semester time span without additional inputs such as high school or transfer credits and/or summer courses. Many students do not think the profession is worth this level of effort (compared to others) or they may have other constraints, such as a minimal grade point average (GPA) in order to maintain a scholarship. Other students simply find the threshold courses unappealing or courses in other majors more appealing. What distinguishes this group overall is that they are not considering the profession itself, but instead the preparation for the profession. The responses within this category fell into three descriptive groups: students who found 1) engineering courses to be too difficult, or felt that the curriculum would take too long, 2) engineering courses to be unappealing, and/or 3) other courses to be more appealing.

Importance of the personal or relational aspect. A small number of students responded by talking about people, typically one person who has attracted them to another field or a person who has turned them off from engineering, often at the institutional level. For this set of students, what matters most are the people, or the kind of people, that they will be working with during their college career and/or their professional lives.

Self-awareness of one's gifts and passions. As one student honestly admitted: "As a freshman I had no clue what I wanted to do. I think the freshman year is too young (sic) to decide what to do with the rest of your life." But as this student and many others reported, the first year was a time of increased awareness of where one's passions lay, as usually expressed in what brings someone joy, e.g., "It fits more with my personality" and "I feel very strongly about conservation of natural resources". Some of these 
revelations came about directly as a result of the threshold engineering courses, and some from effective advising. Responses within this category could be described in three groups: 1) factors relating to a student's original motivation to pursue engineering, 2) a student's core strengths, and/or 3) a student's core passions or enjoyment of activities.

Institutional aspect was predominant. For a small subset of students, a disappointment with an engineering department or program, as an institution, itself was expressed as a reason for leaving. This was expressed as an experience of lack of organization, poor instructors, or the need for "more instructors" so that one could get his graded work back in a more timely fashion.

Researchers sometimes speak of a "hierarchy" of categories within the outcome space. When studying students who were given texts to read, Marton and Booth noticed that some learners focused on the "sign", e.g., the text that is read, or the problems that are given. This was considered by the authors to be a surface approach and has some similarity to a surface learning mentioned in engineering education - an emphasis on the variables or equation to be used to solve a particular problem, rather than the fundamental concept applied. Conversely, other learners focused on the "signified", e.g., what the text is about or what concepts the problem points toward. In engineering circles, the student might be asking "why is this equation appropriate?" and "why are these variables included and not others?",

A hierarchy of categories might be approached with the results of these exit surveys as well. For example, the group that focused on curriculum rather than the profession might be considered as choosing the "sign" over what is "signified," constituting a "surface" approach rather than a "deep" approach to a career. Those students who are encumbered by relational or institutional barriers might even be one further step removed, for their focus is not even on the courses themselves, or on the content of the curriculum and preparation, but rather on their discomfort or dissatisfaction with its delivery.

\section{Results}

A total of 394 students completed Exit Surveys between Fall 2002 and Fall 2006. Of these, $80.3 \%$ were male and $19.7 \%$ were female, which is comparable to the gender split for the overall population of students in the program at that time $(82 \%$ male and $18 \%$ female). Frequency of responses to close-ended questions survey questions were calculated based on the number of students who responded to each particular question, since students could choose more than one response to. Results are summarized graphically in Figures 2 and 3. Out of the students who indicated their new majors $(n=377)$, the highest percentage of students transferred to Business $(n=138 ; 36.6 \%)$, followed by "Other STM" (n=76;20.2\%), which included mathematics, and physical and life sciences. The most common reason cited for leaving by far was "more interested in another field" ( $\mathrm{n}=336 ; 85.4 \%$ of respondents). The most common factor in making this decision was one or more of the first year engineering courses $(n=173 ; 43.9 \%$ of respondents). 


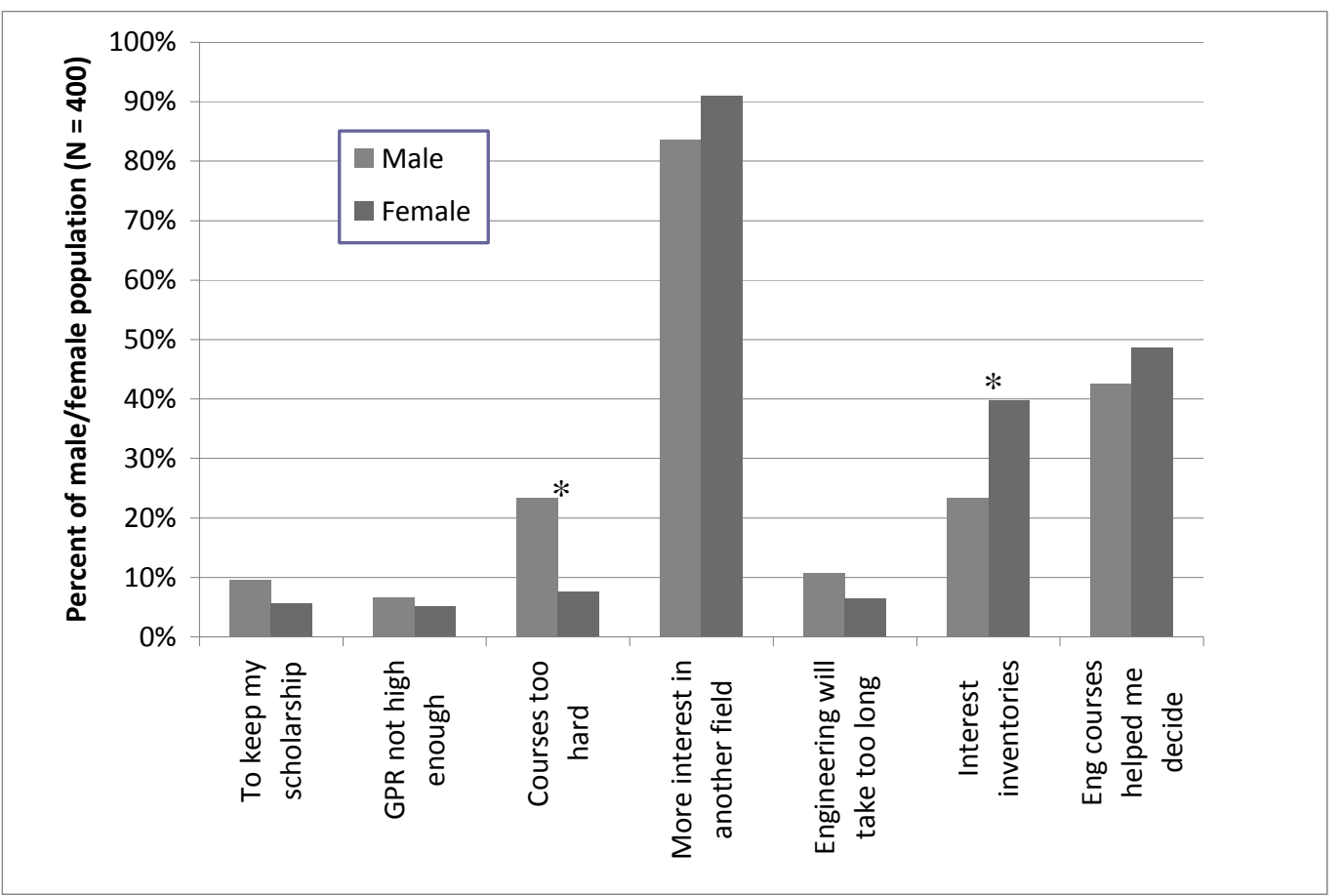

Figure 2. Responses to the close-ended question, "Why did I leave engineering?", showing comparisons between male and female students.

* indicates significant differences.

Responses to close-ended questions yielded significant differences between male and female students. Specifically, significantly more females than males were not very certain about their decision to pursue engineering upon entering the program, and conversely, significantly more males were very certain about this decision. When making the decision to leave engineering, significantly more females than males indicted that results from interest inventories were helpful. More male than female respondents cited the difficulty of their courses as a deciding factor in leaving engineering.

The effect of students' level of certainty upon entering the program on their reasons for leaving paralleled male/female response comparisons. As stated above, more males were very certain that they wanted to be engineers, and that they found the courses too hard; similarly, more students who responded that they were "very certain" upon entering cited the difficulty of courses as a factor in their decision to leave engineering. A related finding was that significantly more of these "very certain" students thought engineering will take too long to complete. 


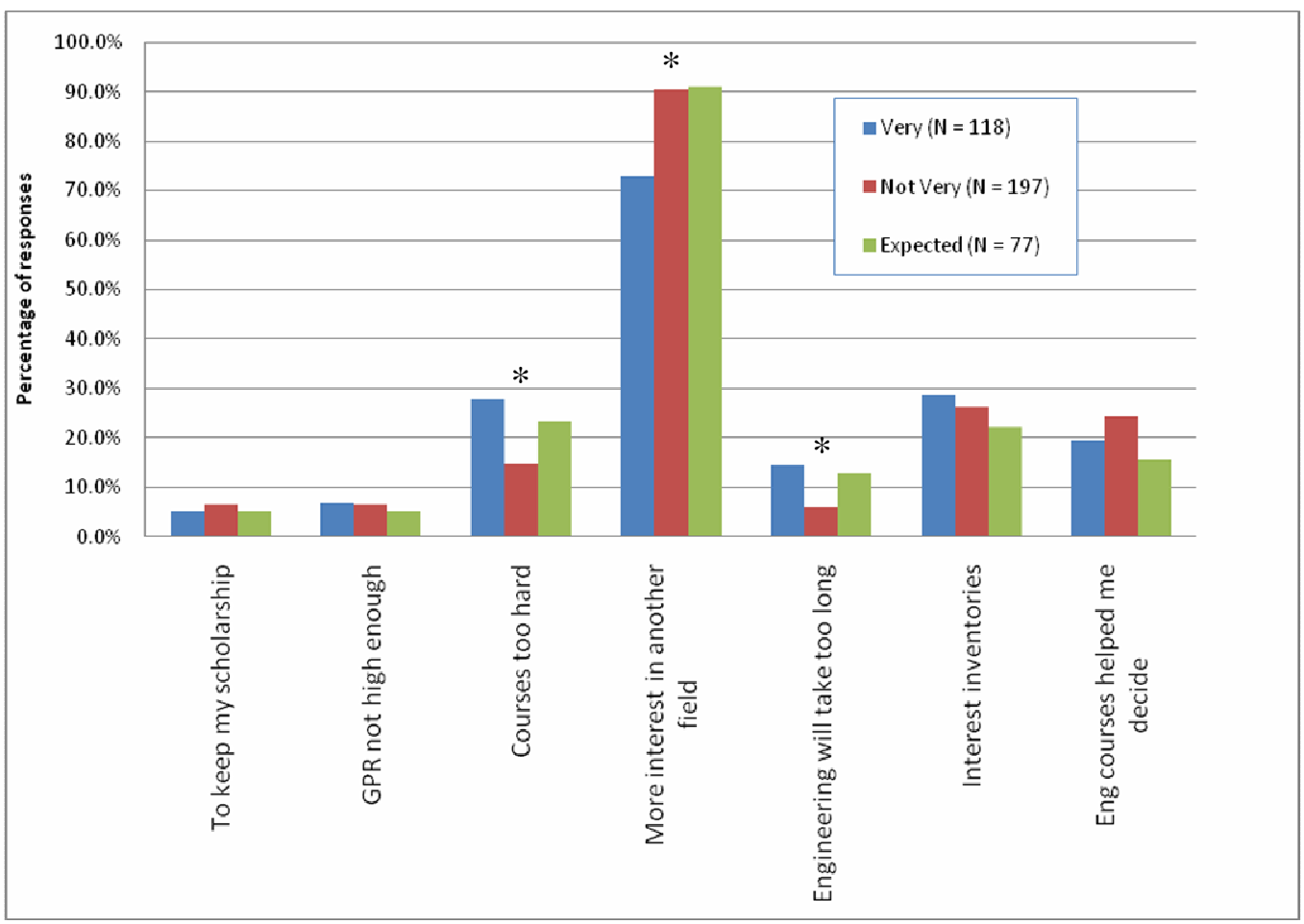

Figure 3. Responses to the close-ended question, "Why did I leave engineering?", showing comparisons between the level of certainty that students had upon entering the first year engineering program. * indicates significant differences.

For students who indicated that they left engineering because they were simply more interested in another field, a significantly fewer number said they were very certain about pursuing engineering upon entry than those responded that they were expected to pursue engineering, or that they were not very certain.

Open-ended responses revealed that students often think in terms of profession, whether engineering or non-engineering, as $39.3 \%$ of the responses fall into this category (Figure 4). (Student responses may invoke more than one category of description.) Of this number, the largest group ( $81 \%$ ) felt pulled toward another profession rather than pushed out of engineering. The next most common responses fell into the category of curriculum (32\%) and self-awareness $(24.8 \%)$. In both of these categories, the students often felt drawn more towards another curriculum and became more in touch with their own core passions and enjoyments. 


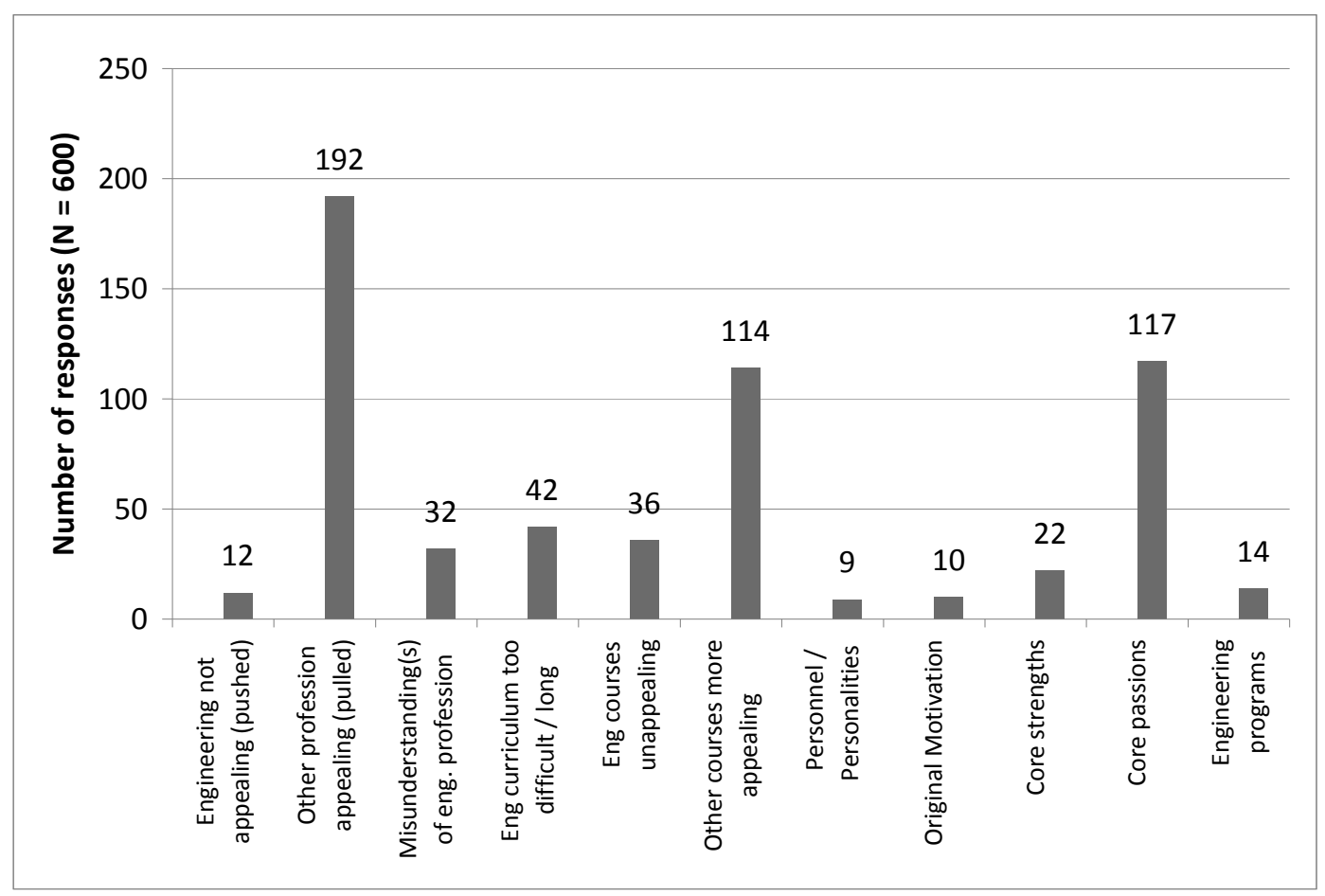

Figure 4. Student responses grouped into categories of description.

\section{Discussion}

Responses to the close-ended survey questions provide some insight into the types of students who are choosing to leave engineering at our institution. A slighter higher percentage of the female GE student population chose to leave engineering than the male population; this may be explained in part by the fact that a larger percentage of male students came into the program very certain that they wanted to pursue engineering. Since more female students were not very certain about the decision to become an engineer, it is not surprising that significantly more of them who left were attracted to other fields, and significantly fewer found the courses too hard. It is possible that they weren't sure about their decision because they did not know what to expect, in which case challenging courses, or a program that might take longer than four years, would not come as a surprise. Whereas males, a higher percentage of whom were very certain upon entry, may have had a misguided impression of what the field was like, or the rigor of the courses, which led to their disenchantment with the field and/or program.

Response analysis of the open-ended survey questions presents a contrast to other research into the reasons why students switch from science or engineering majors to other fields. Seymour and Hewitt discovered that poor teaching and inappropriate reasons for choosing engineering (original motivation) were primary reasons that students left, with inadequate advising not far behind ${ }^{3}$. With our study of open-ended responses, poor teaching was not often cited $(<2.3 \%)$, nor was original motivation $(1.7 \%)$. Advising fared very well with no negative responses and many positive responses on the surveys. This indicates a level of success with the instruction and advising components of our program. 
However, more emphasis should be placed on what specific disciplines of engineering actually do, and how they benefit society.

Some differences in patterns of student responses may be related to the characteristics of the current generation of students who were included in this study. The so-called "millenials" are one of the most studied and self-aware groups of individuals in history". The self-awareness category was one of the most frequently cited as a reason for leaving engineering. It should come as no surprise that these students have arrived at college already familiar with the idea of identifying their interests and strengths, and fully understand the importance of these factors when choosing a course of study and future career.

We suspect that much of the positive nature of responses are a result of the way the question was asked: What do I like about my new major? When framed thus, a student naturally focuses on the positive aspects of his/her new field, whether as profession, curriculum, or a place of newfound enjoyment. Further correlations between the responses to open-ended and closed-ended questions may reveal a truer picture of the primary thrust(s) causing a person to leave engineering.

The survey itself has limitations. One is that some of the questions lead to certain types of responses, such as positive nature of the question listed above (What do I like about my new major?) Also, because students included their names on surveys, they may not be completely truthful. Although we did not observe any hesitation on the part of any student to express him/herself honestly, this does present a possible limitation of this tool. Survey questions and methods of collection will be further studied and validated in future studies, and will consider the possibility of online, anonymously submitted surveys.

Assessment based on the qualitative responses alone has some limitations, because only one pointed question was asked, an interview was not conducted, and mostly short answers were given. Subjective categorization then relied on a collection of short sentences and incomplete phrases, rather than reasoned and reflective thought.

\section{Conclusions}

At Clemson University, the General Engineering curriculum was recently modified to include presentations given by each engineering discipline department on campus. Through academic advising and career counseling, the program helps students discover the career path that is right for them. Future directions for this study will examine the effects of those program changes on retention rates, and on students' impressions of engineering as a career. We will also research ways to refine our survey to be a more robust research tool.

Acknowledgements: The authors would like to thank Elizabeth Crockett for her assistance with this project. 


\section{Bibliography}

1. Goodchild, F.M. “The Pipeline: Still Leaking.” American Scientist 92, no. 2 (2004): 112-113.

2. Besterfield-Sacre, Mary, et al. "Characteristics of Freshman Engineering Students: Models for Determining Student Attrition in Engineering.” Journal of Engineering Education 86, no. 2 (1997): 139-149.

3. Seymour, Elaine and Nancy M. Hewitt. Talking About Leaving: Why Undergraduates Leave the Sciences. Boulder, Co.: Westview Press, 1997.

4. Lichtenstein, Gary, et al. "Should I Stay or Should I Go? Engineering Persistence is Based on Little Experience or Data.” ASEE. AC 2007-1234. 2007.

5. Akerlind, Gerlese. "Variation and Commonality in Phenomenographic Research Methods." Higher Education Research \& Development. 24, no. 4 (2005): 321-334.

6. Marton, Ference and Wing Yan Pong. "On the Unit of Description in Phenomenography." Higher Education Research \& Development. 24, no. 4 (2005): 335-348.

7. Marton, Ference and Shirley Booth. Learning and Awareness. The Educational Psychology Series. Mahwah, N.J.: L. Erlbaum Associates, 1997.

8. Howe, Neil and William Strauss, Millenials Rising: The Next Great Generation. New York, NY: Vintage Press, 2000. 